\title{
Depressed skull fracture at Pacopampa in the Peru's northern highlands in the Late Cajamarca Period
}

\author{
Tomohito NAGaOKA $^{1 *}$, Yuji Seki ${ }^{2}$, Mauro Ordoñez Livia ${ }^{3}$, Daniel Morales ChocAnO ${ }^{3}$ \\ ${ }^{1}$ Department of Anatomy, St. Marianna University School of Medicine, 2-16-1 Sugao, Miyamae Ward, Kawasaki, Kanagawa \\ 216-8511, Japan \\ ${ }^{2}$ National Museum of Ethnology, 10-1 Senri Expo Park, Suita, Osaka 565-8511, Japan \\ ${ }^{3}$ Universidad Nacional Mayor de San Marcos, Lima 15081, Peru
}

Received 7 February 2020; accepted 6 April 2020

\begin{abstract}
The Pacopampa site is one of the largest Formative Period sites in Peru's northern highlands. In the 2013 field season, we uncovered human remains from the stairs between the second and third platforms and found a rare case of a depressed skull fracture on the cranial vault of a middle-aged male. This study aims to describe the fracture and explore chronological changes in violence in Peru's northern highlands. The radiocarbon date of this male is $910 \pm 30{ }^{14} \mathrm{C} \mathrm{yr} \mathrm{BP}$, which corresponds to the Late Cajamarca Period (AD 950-1200). The fracture is elliptical in shape, $23.7 \mathrm{~mm}$ long and $23.3 \mathrm{~mm}$ wide. Depressed debris, adhering to part of the vault, entered the cranial cavity and may have compressed dura mater and brain substance. A healing reaction formed a smooth edge around the fracture, suggesting that it is an antemortem fracture and that the individual survived the injury. It is reasonable to infer that the presence of trauma on the Pacopampa cranium is consistent with the sociopolitical background, typified by high social tension and the appearance of organized warfare in Andean societies.
\end{abstract}

Key words: Andean civilization, bioarchaeology, fracture, Pacopampa, violence

\section{Introduction}

The bioarchaeology of trauma provides clues to assessing societies' influence on human behavior, and human skeletons with traumatic injuries serve as direct evidence of violence (Larsen, 2015). Andean civilization experienced multiple empires until the end of Inca in 1532 and was closely linked with warfare and violence (e.g. Tung, 2007). However, little is known about chronological and regional variation in violence-related trauma in Andean civilization. Bioarchaeological study of the human skeletons from various archaeological settings in the Andes would refine our understanding of warfare and violence.

The Pacopampa site is one of the largest Formative Period sites in Peru's northern highlands (Figure 1a). The Pacopampa Archaeological Project, directed by Yuji Seki and Daniel Morales Chocano, has conducted the excavation of Pacopampa since 2005. The site is composed of three large platforms and covers a total area of about 4 hectares (Figure 1b). Three low platforms surrounding a sunken plaza were constructed and renovated in the Middle Formative Period (Pacopampa I phase; 1200-700 BC) and the earlier half of

\footnotetext{
* Correspondence to: Tomohito Nagaoka, Department of Anatomy, St. Marianna University School of Medicine, 2-16-1 Sugao, Miyamae Ward, Kawasaki, Kanagawa 216-8511, Japan.

E-mail: nagaoka@marianna-u.ac.jp

Published online 10 July 2020

in J-STAGE (www.jstage.jst.go.jp) DOI: 10.1537/ase.2004061
}

the Late Formative Period (Pacopampa II phase; 700-400 $\mathrm{BC})$. The presence of large-scale public architecture and a plaza, decorated stone sculptures, and archaeological remains related to rituals support the idea that this site functioned as a ceremonial center (Seki et al., 2010). The ceremonial center, however, ceased functioning in the Final Formative Period (250-50 BC), but the ruins continued to be a place of ritual during the Early Cajamarca Period (AD 200-450) (Nagaoka et al., 2019). In the 2013 field season, a burial was unearthed from a layer that had been deposited as the stairs collapsed, either deliberately or naturally, and an individual with a depressed skull fracture on the cranial vault was detected. As mentioned below, the individual belonged to the Late Cajamarca Period (AD 950-1200), by which time the ceremonial center had ceased its function. This study aims to describe this case of fracture in Peru's northern highlands and to compare it with previous cases.

\section{Materials and Methods}

A depressed skull fracture was detected on the individual (13PC-G-Ent 1-H1), who was not associated with burial goods (Figure 1c). The materials used in this study were curated by the Pacopampa Archaeological Project and temporarily housed at the Center for Pacopampa Archaeological Project (Jr. Bolognesi, Centro Poblado de Pacopampa, Distrito de Querocoto, Provincia de Chota, Region Cajamarca, Peru) with the permission of the Peruvian Ministry of Culture. 

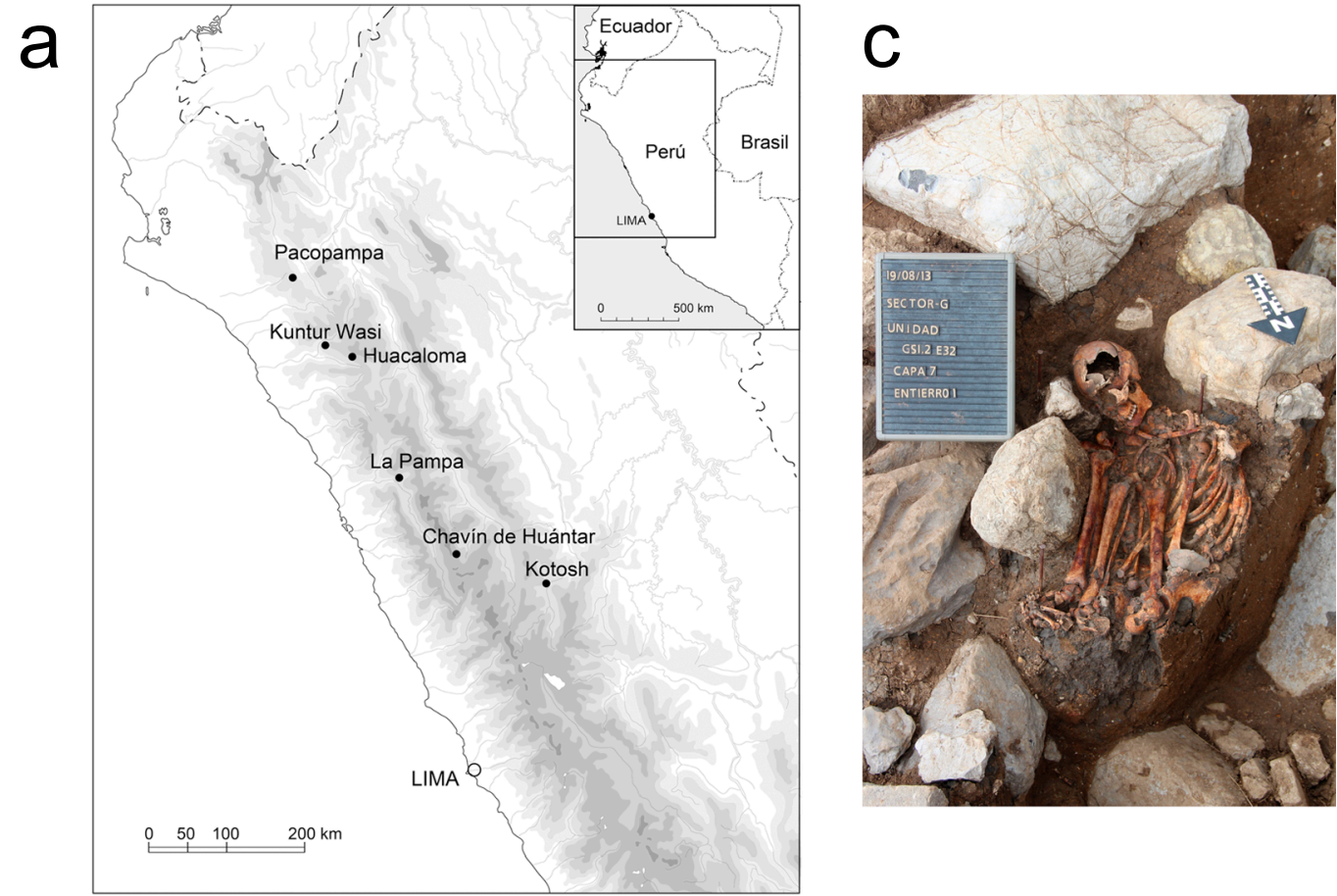

\section{b}

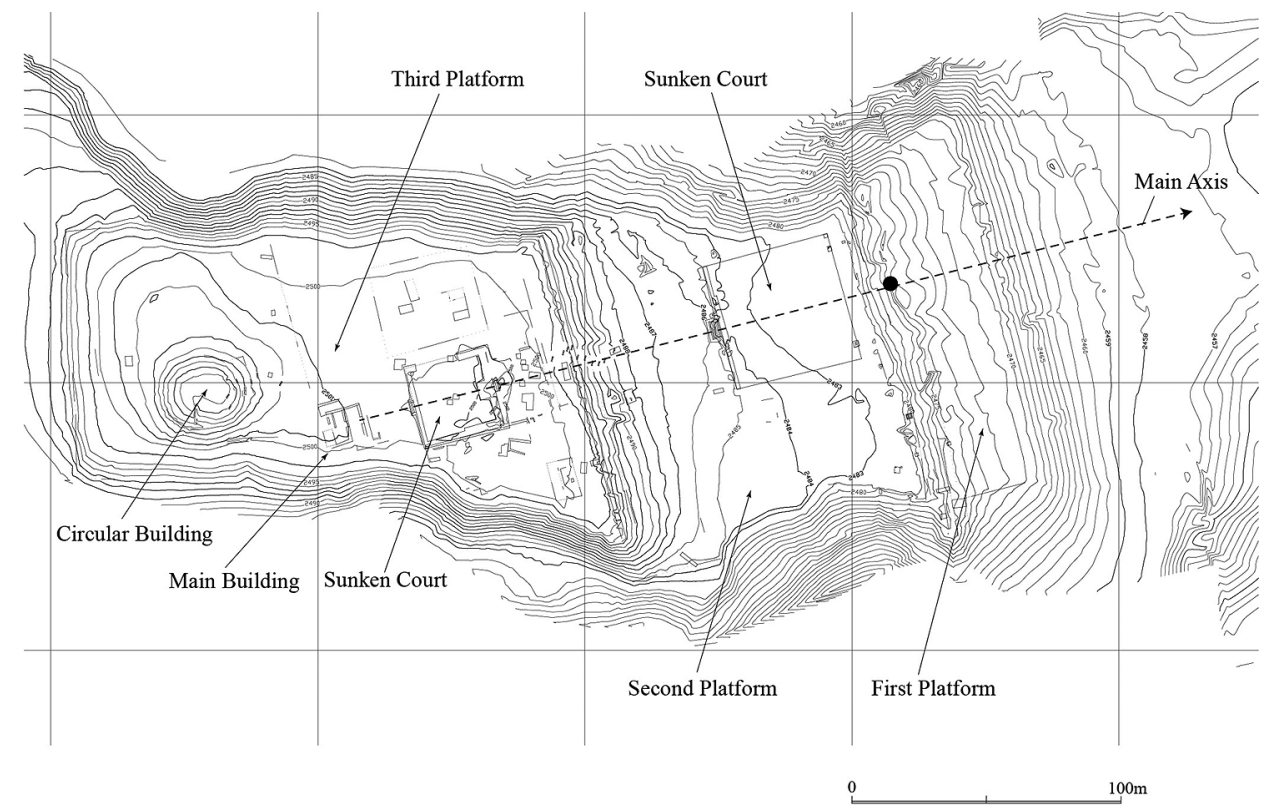

Figure 1. (a) Map of Peru showing the location of Pacopampa. (b) Map of the ceremonial complex at Pacopampa; the black circle shows the location of the tomb of 13PC-G-Ent 01. (c) The tomb of 13PC-G-Ent 01, a male individual with a head trauma.

Radiocarbon dating of the bones was performed by Beta Analytic (Miami, FL, USA), and the IntCal13 dataset was used to calibrate the radiocarbon ages (Bronk Ramsey, 2009). The adult's skeletal age at death was estimated based on the chronological metamorphosis of the auricular surface of the ilium (Lovejoy et al., 1985; Buckberry and Chamberlain, 2002) and dental wear (Lovejoy, 1985). The sex of the adult individual was determined through a macroscopic assessment of pelvic and cranial traits (Bruzek, 2002; Walker,
2008).

The fracture was macroscopically examined. Radiographic analyses were unavailable because the permission granted by the Peruvian Ministry of Culture did not permit transportation of skeletal remains outside of the country to our institutions for analyses. The locations, mechanisms, healing, and complications of the fracture were all considered (Aufderheide and Rodríguez-Martín, 1998; Rockwood et al., 1991). 


\section{Results}

The radiocarbon date $\left(910 \pm 30{ }^{14} \mathrm{C}\right.$ yr BP $)$ of $13 \mathrm{PC}-\mathrm{G}-$ Ent 1-H1 corresponded to the Late Cajamarca Period (AD 950-1200), although cultural remains such as pottery belonging to the Late Cajamarca Period were not associated to the burial.

This individual was determined to be male from the diagnostic features of the pelvic bones - the asymmetric greater sciatic notch and single composite arc. Remarkable projection in the nuchal region and mastoid processes supports the diagnosis. The individual was estimated to be middle-aged (35-54 years) from the fifth stage in Lovejoy et al.'s (1985) auricular surface system, the fifth stage in Buckberry and Chamberlain's (2002) auricular surface system, and the E stages in Lovejoy's (1985) dental wear system. Stature was estimated using the equations outlined by Genovés (1967), which utilize the maximum length of the femur. The individual's estimated stature was $165.8 \mathrm{~cm}$ based on Genovés' equations for the maximum length of femur $(440 \mathrm{~mm}$, right femur). The crown surfaces of the 26 teeth were moderately worn out. Caries lesions were found in 8 of the 26 teeth (30.8\%).

13PC-G-Ent 1-H1 exhibited a depressed fracture in the posterior half of the right parietal bone. The shape is elliptical, $23.7 \mathrm{~mm}$ long and $23.3 \mathrm{~mm}$ wide (Figure 2a). Depressed debris, adhering to part of the vault, entered the cranial cavity and may have compressed dura mater and brain substance (Figure 2b). The wound was a blunt-force fracture produced by the direct application of force to the cranial vault. Nutrient vascular foramina were observed in the fractured part (Figure $2 \mathrm{~b}$ ) and the internal table revealed striations radiating from the depression (Figure 2c), which are indicative of new bone formation during the healing process. A healing reaction resulted in the formation of a smooth edge around the fracture, which suggests that it is an antemortem fracture and that the individual survived the injury. We did not detect any fracture to the hand and foot bones and ribs, which indicates a biased distribution of fractures to the body.

\section{Discussion}

The affected individual is a middle-aged male with a depressed skull fracture in the posterior half of the right parietal bone. This individual may have been assaulted by a right-handed attacker from the posterior direction. Reviewing the study data and its comparisons (Supplementary Table 1), the Pacopampa site exhibited depressed skull fractures both in the Formative and Cajamarca Periods out of 65 skulls recovered. The present and previous cases did not exhibit any difference in morphology, healing processes, and poor alignments. Female skulls had depressed injuries in the Pacopampa I and II phases, while males became often involved in violence in the later dates (Supplementary Table 2).

Depressed skull fractures were likely produced by intentional violent behavior, and the round depression fractures were likely caused by close-proximity assaults with slingstones or thrown rocks (Arkush and Tung, 2013). Here, organized warfare is one possible explanation for the presence of the depressed skull fracture. After AD 600, the rise and fall of state polities led to an increase in territorial conquest and warfare in the Central Andes. The warfare and violence became the most intense in AD 1000-1450, an intermediate period between the Middle Horizon state of the Wari (AD 600-1000) and the Late Horizon state of the Inca (AD 1450-1532) in the Central Andes. These periods nearly cor-

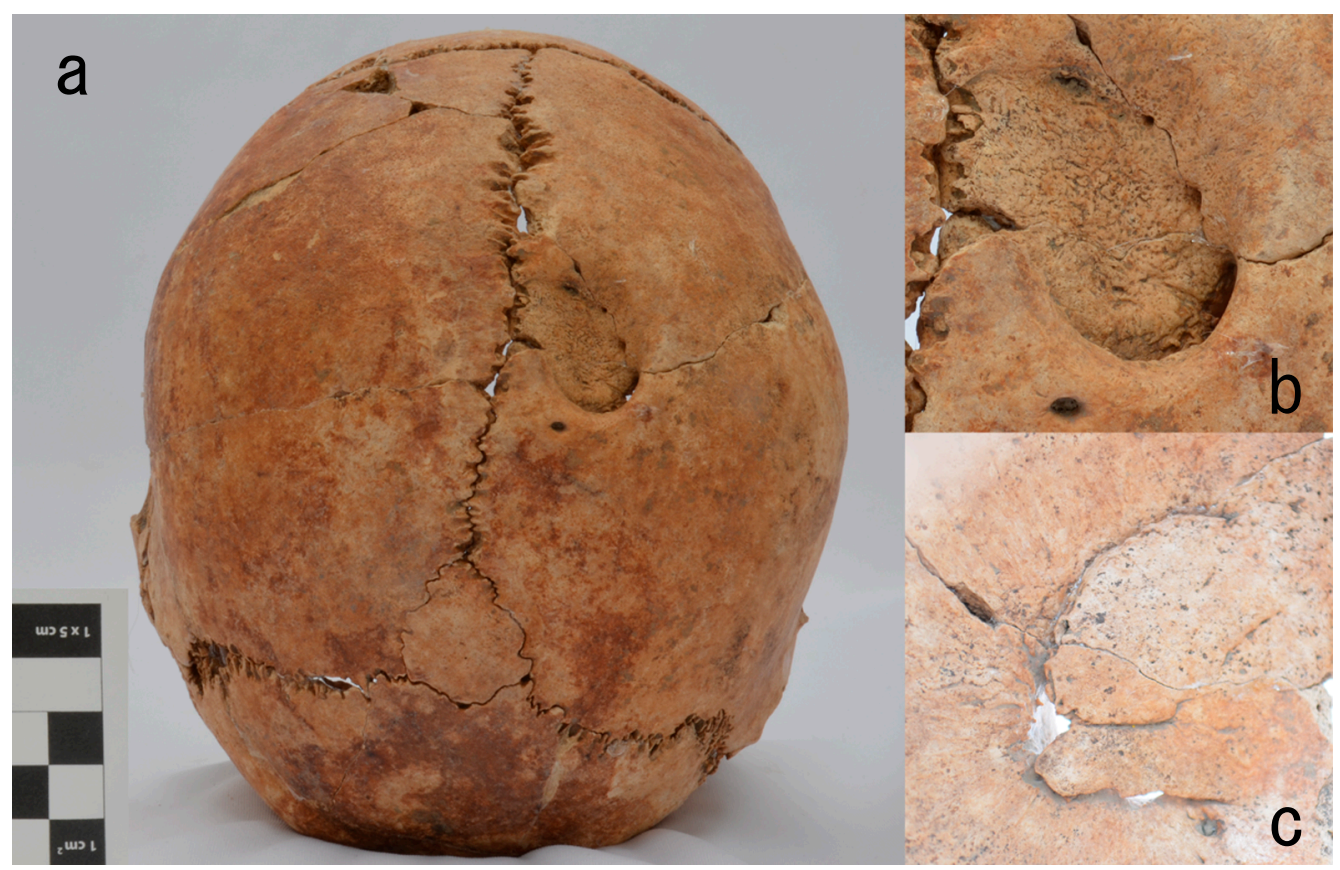

Figure 2. (a) Depressed skull fracture in the right parietal bone of 13PC-G-Ent 01, (b) a magnification of the fracture from the superior view, and (c) a magnification of the fracture from the inferior view. 
respond with the Late Cajamarca Period in the northern highlands, the radiocarbon date of the present material. Political integration of the lower valleys under centralized hegemony lessened conflicts there, but polities were small in the central and southern highlands and inhabitants were often involved in fierce violence (Arkush and Tung, 2013). Unfortunately, the sociopolitical context of the Late Cajamarca Pacopampa is still unknown, but hilltop settlements and fortifications appeared in Cajamarca in the northern highlands during these periods (Arkush and Tung, 2013). It is reasonable to infer that the presence of trauma on 13PC-GEnt 1-H1 is consistent with this sociopolitical background.

Increasing social tension and the appearance of organized warfare in Andean societies were linked to ritual violence. Moche (AD 100-800) iconography depicts capturing prisoners, mutilations, sacrifices, and dismemberments in highly ritualized conflicts (Donnan, 1976). The traumatic pattern found in this study is similar to that found at La Real, Wari (Tung, 2007, 2012) caused by a ritual battle called tinku. Men frequently participated in tinku; combatants fought face to face or threw stones at each other; spilling blood during battle was regarded as an offering to the earth to pray for fertility (Tung, 2007, 2012). These fights may not have caused lethal wounds and they were not associated with parry fractures of the forearm (Tung, 2012). The severe but healed traumas concentrated on the cranium, and without defensive wounds, that were found in several cases at Formative Period Pacopampa appear to have been a result of fierce forces applied under controlled conditions (Nagaoka et al., 2017). The depressed skull fracture detected in this study showed evidence of healing and was not associated with parry fractures of the forearm, which is common to the cases in the Formative Period Pacopampa. The similarity between this and Formative Period cases does not exclude the possibility that the affected individual was involved in violence in the context of rituals. The Pacopampa site continued to be a place of rituals during the Formative Period and possibly even later, although the individual was not a person who was in charge of rituals during the period when the ceremonial center ceased its functions. Regardless of whether the affected individual was involved in ritual violence or not, it is safe to say that the depressed skull fracture shown in this study is a rare case of violence-related trauma in the Late Cajamarca Period.

\section{Author contributions}

T.N. designed the research, collected and analyzed the data, and wrote the paper. Y.S. conducted the Pacopampa Archaeological Project and revised the paper. M.O.L excavated the tomb. D.M.C. conducted the Pacopampa Archaeological Project.

\section{Acknowledgments}

The authors would like to express their gratitude to Professor K. Uzawa, Ms M. Arata, and Ms N. Nakagawa for their invaluable help. This study is supported by the Japanese Society for the Promotion of Science (JSPS) KAKENHI (grant numbers $23222003,15 \mathrm{~K} 07241,16 \mathrm{H} 02729$, and 16H05639).

\section{Ethical Standards}

The materials and methods of this study did not require approval by the ethics committee of our institute. All necessary permits were obtained for the described study from the Peruvian Ministry of Culture (permission no. 006-2013DGPA-VMPCIC/MC).

\section{Conflict of interest}

The authors declare that they have no conflict of interest.

\section{References}

Arkush E. and Tung T.A. (2013) Patterns of war in the Andes from the Archaic to the Late Horizon: insights from settlement patterns and cranial trauma. Journal of Archaeological Research, 21: 307-369.

Aufderheide A.C. and Rodríguez-Martín C. (1998) The Cambridge Encyclopedia of Human Paleopathology. Cambridge University Press, Cambridge.

Bronk Ramsey C. (2009) Bayesian analysis of radiocarbon dates. Radiocarbon, 51: 337-360.

Bruzek J. (2002) A method for visual determination of sex, using the human hip bone. American Journal of Physical Anthropology, 117: 157-168.

Buckberry J.L. and Chamberlain A.T. (2002) Age estimation from the auricular surface of the ilium: a revised method. American Journal of Physical Anthropology, 119: 231-239.

Donnan C.B. (1976) Moche Art and Iconography. UCLA Latin American Studies Publications, University of California, Los Angeles.

Genovés S. (1967) Proportionality of the long bones and their relation to stature among Mesoamericans. American Journal of Physical Anthropology, 26: 67-78.

Larsen C.S. (2015) Bioarchaeology: Interpreting Behavior from the Human Skeleton. Cambridge University Press, Cambridge.

Lovejoy C.O. (1985) Dental wear in the Libben population: its functional pattern and role in the determination of adult skeletal age at death. American Journal of Physical Anthropology, 68: 47-56.

Lovejoy C.O., Meindl R.S., Pryzbeck T.R., and Mensforth R.P. (1985) Chronological metamorphosis of the auricular surface of the ilium: a new method of determining adult age at death. American Journal of Physical Anthropology, 68:15-28.

Nagaoka T., Uzawa K., Seki Y., and Morales Chocano D. (2017) Pacopampa: early evidence of violence at a ceremonial site in the northern Peruvian highlands. PLoS ONE, 12: e0185421.

Nagaoka T., Takigami M., Seki Y., Uzawa K., Alemán Paredes D., Andía Roldán P.S., and Morales Chocano D. (2019) Bioarchaeological evidence of decapitation from Pacopampa in the northern Peruvian highlands. PLoS ONE 14: e0210458.

Rockwood C., Green D., and Bucholz R. (eds.) (1991) Fractures in Adults. J.B. Lipponcott Company, Philadelphia, PA.

Seki Y., Villanueva J.P., Sakai M., Alemán D., Ordóñez M., Tosso W., Espinoza A., Inokuchi K., and Morales D. (2010) Nuevas evidencials del sitio arqueológico de Pacopampa, en la sierra norte del Perú. Boletín de Arqueología PUCP, 12: 69-95.

Tung T.A. (2007) Trauma and violence in the Wari Empire of the Peruvian Andes: warfare, raids, and ritual fights. American Journal of Physical Anthropology, 133: 941-956.

Tung T.A. (2012) Violence, Ritual, and the Wari Empire: A Social Bioarchaeology of Imperialism in the Ancient Andes. University Press of Florida, Gainesville.

Walker P.L. (2008) Sexing skulls using discriminant function analysis of visually assessed traits. American Journal of Physical Anthropology, 136: 39-50. 

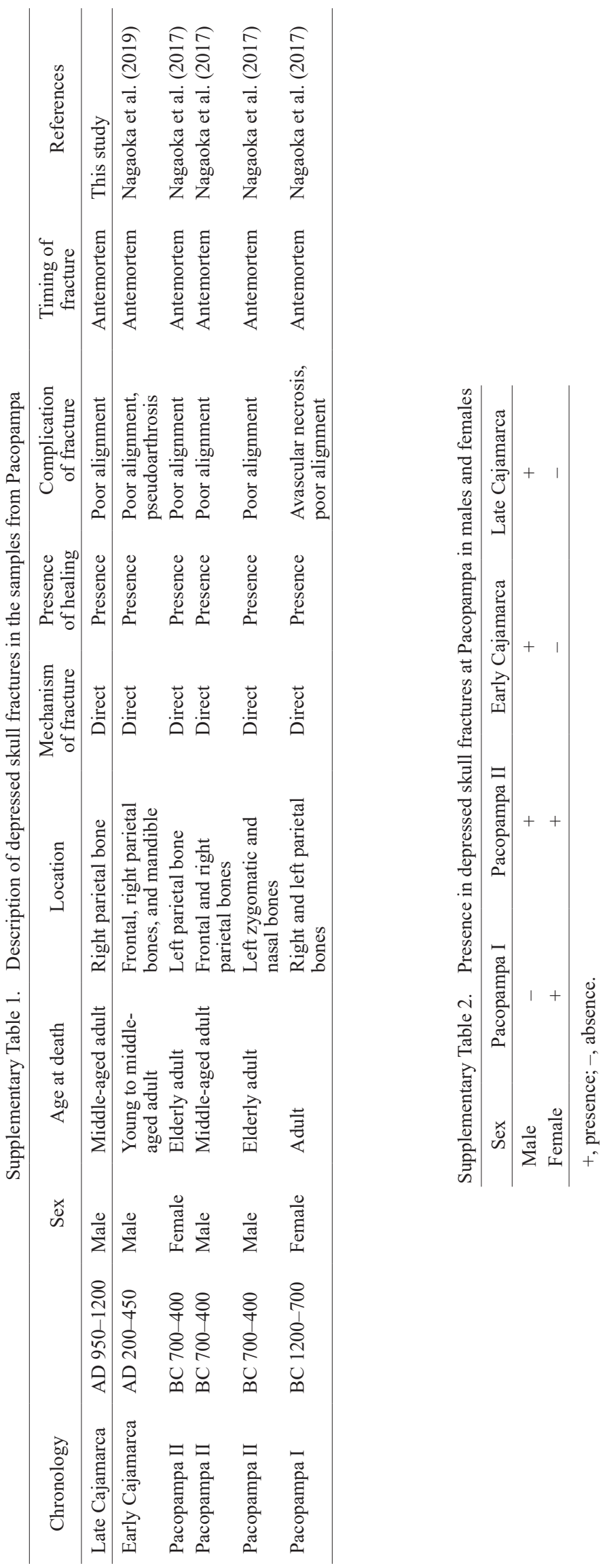